\title{
A CULTURA MACHISTA E OS PREJUÍZOS AOS DISSIDENTES OU DIVERGENTES DAS QUESTÕES SEXUAIS E DE GÊNERO
}

\section{Resumo:}

\section{Paulo Roberto de Souza Junior ${ }^{1}$}

Este artigo enfoca a questão da cultura machista e os prejuízos aos dissidentes ou divergentes da questão sexual e de gênero devido à omissão de debates sobre a temática nos diversos campos de luta e fala existentes. O presente estudo utiliza a pesquisa qualitativa de cunho bibliográfico, na busca da (des)construção dos elementos que corporificam esta cultura que é machista, fundamentalista, conservadora e patriarcal visando o respeito aos direitos das minorias em debate. Os resultados permitem concluir haver necessidade deste enfrentamento para garantia dos direitos aos referidos dissidentes ou divergentes.

Palavras-chave: minorias de gênero; minorias sexuais; cultura machista; patriarcalismo

\section{SEXIST CULTURE AND DAMAGE TO DISSENTERS OR DISSENTERS ON SEXUAL AND GENDER ISSUES}

\begin{abstract}
:
This article focuses on the issue of sexist culture and the damage to dissidents or divergent sexual and gender issues due to the omission of debates on the subject in the various fields of struggle and speech. The present study uses qualitative bibliographic research, in the search for (dis)construction of the elements that embody this culture that is sexist, fundamentalist, conservative and patriarchal aiming at respect for the rights of minorities under debate. The results allow us to conclude that there is a need for this confrontation to guarantee the rights of these dissidents or divergent.
\end{abstract}

Keywords: gender minorities; sexual minorities; macho culture; patriarchy

\section{1- Introdução}

Este artigo traz como preocupação central a análise da cultura machista e os prejuízos deste posicionamento perante aos dissidentes ou divergentes da questão de gênero devido ao não respeito ao seu local de fala, nem a sua dignidade e performances. Trata-se de um debate acerca da cultura machista e suas consequências dentro da questão de gênero.

A questão do "machismo", segundo Oliveira, Lima e Gomes (2018) estuda:

“[...] que se quer abordar neste estudo está atrelada aos elementos culturais, perpetuados através do processo de socialização, que está

\footnotetext{
${ }^{1}$ Doutorando em Humanidades, Culturas e Artes (UNIGRANRIO). Mestre em Direito. Pós Graduando em Direitos Humanos, Responsabilidade Social e Cidadania (PUCRS). Esp. em Planejamento Educacional e Políticas Públicas, Gênero e Sexualidade, Gestão da Saúde Pública, Gestão Hospitalar, Direito Tributário, Direito Constitucional, e, Direito da Cidade. Professor da ETEOT/FAETEC e SEEDUC/RJ. E-mail: pauloroberto.coordenacao@gmail.com.
} 
para além da relação binária heteronormativa. Neste sentido, este estudo parte da concepção de "cultura machista", ou seja, modos e padrões comportamentais, assimilados e/ou reproduzidos pelos sujeitos, com o intuito de subjugar, silenciar, "desmoralizar", impor uma determinada conduta, tendo como princípio norteador a ideia de superioridade do masculino em detrimento do feminino.

(OLIVEIRA, LIMA E GOMES, 2018, p. 68).

Desta forma, temos como hipótese a seguinte afirmação: a avaliação de posicionamentos heteronormativos que apoiam uma cultura machista, em tempos atuais e, por isso, não privilegiando aos estudos de gênero, ou seja, a influência do (neo)conservadorismo e o (neo)fundamentalismo dentro das construções sociais definidas pelos tais estudos.

No Dicionário de política, de Bobbio, Matteucci e Pasquino (2000), o termo conservadorismo designa "ideias e atitudes que visam à manutenção do sistema político existente e dos seus modos de funcionamento, apresentando-se como contraponto das forças inovadoras" (BONAZZI, 2000, p. 243).

A influência deste "pensamento fundamentalista e (neo)conservador" é, na verdade, o conjunto de teorias que versam sobre a questão da "ideologia de gênero, conceito criado pela Igreja Católica e aceito pelas Igrejas Pentecostais no Brasil.

O mencionado conservadorismo é visto "como uma visão social do mundo (LOW, 2000) cujo discurso se baseia no estilo de pensamento que Manhein (1959) chama de conservador e que tem seu pilar na tradição" (SEPULVEDA; SEPULVEDA, 2018, p. 50). Os neoconservadores contemporâneos são caracterizados na esfera política, como salientado por Bianchi (2016):

"[...] a tentativa de conciliar o autoritarismo próprio da antiga tradição com a democracia representativa, estabelecendo, porém, fortes limites ao funcionamento desta. O caráter plebiscitário da democracia limitada e poder moderador atribuído crescentemente ao Judiciário deveriam garantir que o exercício do sufrágio universal não se traduzisse plenamente na realização da soberania popular. As paixões populares e os interesses dos grupos socais poderiam, assim, permanecer à margem da política, sendo convocados periodicamente apenas para escolher a facção governante. A concepção elitista da política, que sempre acompanhou o conservadorismo, traduziu-se, assim, em uma concepção elitista da democracia representativa". (BIANCHI, 2016, p. 19).

Já o termo "fundamentalismo" segundo Savi (2015, p.12), refere-se à “(...) interpretação literal das revelações do livro sagrado, sejam elas cristãs ou islâmicas, tomada com o princípio estruturante de organização da sociedade, social e política".

O fundamentalismo religioso alega prejuízos morais causados pelos valores seculares, recusando a diversidade moral, cultural e de subjetividade, reivindicando o retorno de práticas sociais tradicionais. Assim, surge como força de oposição à secularização (Chauí,2006; Lionço, 2017; Savi, 2015). 
Estes fundamentalistas estão presentes na política nacional sendo representantes da filosofia neopentecostal ou da Terceira Onda do Pentecostalismo ${ }^{2}$, que tem como base o movimento carismático, aliados aos (neo)conservadores, que não permitem abordagem sobre gênero, diversidade sexual e educação sexual dentro do ambiente escolar, devido à defesa das características da família tradicional heterossexual, por entenderem que é a família que define os debates sobre a questão de gênero.

O mencionado conservadorismo é visto "como uma visão social do mundo (LOW, 2000) cujo discurso se baseia no estilo de pensamento que Manhein (1959) chama de conservador e que tem seu pilar na tradição" (SEPULVEDA; SEPULVEDA, 2018, p. 50). Não sendo outro entendimento de Álvaro Bianchi (2016):

[...] abraçam os valores da sociedade capitalista e fazem do empreendedorismo e da prosperidade de sua ideologia" (op cit, p. 18), enaltecem a ordem e a hierarquia, vê na família a célula fundamental da sociedade e considera a civilização ocidental ameaçada pela secularização de valores. Defendem o movimento

'Escola sem Partido', contestam o ensino da 'ideologia de gênero', atacam a adoção do 'kit-gay' e advogam contra as religiões de matriz africana. As políticas de reconhecimento contrapõem o discurso da negação das diferenças. (BIANCHI, 2016, p. 19).

A principal justificativa deste trabalho é o enfrentamento da cultura machista e patriarcal que busca a não permissão dos estudos de gênero por entender que se trata de uma "ideologia de gênero", conceito criado pela Igreja Católica para discordar destes estudos propostos pelo movimento feminista de segunda onda e acatados pela ONU - Organização das Nações Unidas.

O instrumento utilizado dentro deste estudo será a pesquisa bibliográfica sobre a temática, onde serão apreciados estudos publicados do machismo e sua influência nas questões de gênero, na busca de condições para sintetizar uma análise correta e coerente desta política com finalidade de traçar os referidos caminhos para sua revisão. O texto final foi fundamentado nas ideias e concepções de autores como, JUNQUEIRA (2018), OLIVEIRA, LIMA e GOMES (2018) e SOUZA Jr (2018)

\section{2- O machismo e a sociedade patriarcal}

\footnotetext{
${ }^{2}$ A Terceira Onda teve início no final dos anos 70 e início dos anos 80, e é fortemente caracterizada por um certo afastamento das doutrinas pentecostais clássicas e apego à chamada teologia da prosperidade. Os "NeoPentecostais" como são chamados, adotam formas diferentes de administração e utilizam técnicas de Marketing extremamente eficazes em suas abordagens tendo na mídia seu principal foco. Desta terceira onda, surgiram a Igreja Universal do reino de Deus, Igreja Internacional da Graça de Deus, Igreja Mundial do Poder de Deus, Igreja Renascer em Cristo, Comunidade Sara Nossa Terra, Igreja Paz e Vida, as Comunidades Evangélicas em geral e diversas outras. O Foco da Mensagem é Prosperidade Financeira, bem-estar pessoal, exorcismo etc. (FERREIRA, Jorge A. As 03 Ondas do Pentecostalismo 'Resumo', 31 de maio de 2018, https://opentecostal-reformado.blogspot.com/2018/05/as-03-ondas-dopentecostalismoresumo.html, acesso em 05 de ago de 2018).
}

Revista de Gênero, Sexualidade e Direito | e-ISSN: 2525-9849 | Encontro Virtual | v. 7 | n. 2 | p. $62-76$ | Jul/Dez. 2021. 
A cultura patriarcal heteronormativa é impregnada do machismo, renegando, assim, os direitos das minorias sexuais e de gênero, como mencionado por Souza e Lopes (2019):

"[...] às mulheres foram negados o estudo, o trabalho remunerado e as escolhas particulares, deixando-as por muito tempo confinadas no espaço privado, responsáveis por todas as tarefas domésticas e sem participação política. Depois de muita luta de mulheres por uma libertação patriarcal, alguns pontos mudaram e diretos foram lentamente adquiridos. Mas a sociedade ainda é machista e a cultura é de violência contra a mulher, visto que apesar das mudanças, ainda estamos em uma realidade capitalista cuja lógica transforma quase tudo em mercadoria, até mesmo as mulheres. Abrir espaço para algumas mudanças faz parte inclusive dessa racionalidade capitalista, que tenta se apropriar até mesmo das lutas, cedendo em alguns pontos, para manter sua hegemonia". (SOUZA E LOPES, 2019, p. 24):

O machismo possui como elemento basilar um conjunto de atitudes, comportamentos, percepções de mundo e normatização, cujo principal referencial é o fato da figura masculina se sobrepor, em diversos sentidos.

Este machismo que tem como base a tradição patriarcal se desenvolveu através do disposto em que a mulher é inferior ao homem por isso não pode ter os mesmos direitos dele, cabendo a este ocupar o espaço público e aquelas espaço doméstico, conforme salienta Sepuvelda e Sepulveda (2018, p. 48). Dessa forma a esconde da arena social e de seu local de fala. Segundo Ribeiro (idem, p. 64) "o falar não se restringe ao ato de emitir palavras, mas o poder de existir".

Walby (1990) distingue duas formas de patriarcado, o privado e o público, que se diferenciam conforme as relações e formas assumidas por cada uma delas.

No patriarcado privado, WALBY (1990, p. 178), por um lado, o homem, como pai ou marido, encontra-se na posição de opressor e de beneficiário da subordinação das mulheres, sendo seu principal mecanismo a exclusão das mulheres da esfera pública. No patriarcado público, por outro lado, as mulheres têm acesso às esferas pública e privada, ou seja, sua participação política não é impedida formalmente, como no patriarcado privado; entretanto, a subordinação das mulheres persiste em ambas as esferas, havendo apenas a passagem de uma relação de subordinação privada, como a que ocorre no âmbito doméstico, para uma subordinação coletiva.

Em relação ao conceito de patriarcado pontua Saffioti (2015):

"À medida que as (os) teóricas (os) feministas forem se desvencilhando das categorias patriarcais, não apenas adquirirão poder para nomear de patriarcado o regime atual de relações homemmulher, como também abandonarão a acepção de poder paterno do direito patriarcal e o entenderão como direito sexual. Isto equivale a dizer que o agente social marido se constitui antes que a figura do pai”. (SAFFIOTI, 2015, p. 59).

Acreditamos que a política sexual sob o patriarcado é tão onipresente nas vidas das mulheres negras, quanto às políticas de classe e raça. Também achamos, muitas vezes, difícil 
separar opressões de raça, classe e sexo porque, nas nossas vidas, elas são quase sempre experimentadas simultaneamente. Nós sabemos que existe uma coisa que é uma opressão sexual-racial que nem é somente racial, nem somente sexual, por exemplo, a história do estupro das mulheres negras por homens brancos como arma de repressão política. Mesmo sendo feministas e lésbicas, nos solidarizamos com os homens negros progressistas, e não defendemos o fracionamento que as mulheres brancas separatistas reivindicam. (AKOTIRENE, 2019, p.18).

A tradição patriarcal desenvolveu o disposto em que a mulher é inferior ao homem por isso não pode ter os mesmos direitos dele, cabendo a este ocupar o espaço público e aquelas espaço doméstico, conforme salienta Sepuvelda e Sepulveda (2018, p. 48).

Ao contrário do que pode parecer, o machismo, a cultura patriarcal e a falaciosa inferioridade feminina não são termos anacrônicos, relativos a épocas remotas ou superadas. Trata-se de ideias fundadas na desigualdade entre os sexos, que durante séculos, apoderaramse organicamente de nossa mentalidade (KOLONTAI, 2011, p. 54)

Nesse sentido, a relação de dominação-exploração é base no peso estrutural do patriarcado, de modo algum se esgota no gênero ou na sexualidade.

A dominação constitui um caso especial de poder, caracterizado pela "possibilidade de impor ao comportamento de terceiros a vontade própria" (WEBER, 1991, p. 187), diferenciando-se deste último pela noção de obediência, pela aceitação da ordem dada.

A ‘dominação' refere-se a uma situação de fato, em que uma vontade manifesta

('mandado') do 'dominador' ou dos 'dominadores' quer influenciar as ações de outras pessoas (do 'dominado' ou dos 'dominados') e de fato a influência de tal modo que estas ações, num grau socialmente relevante, se realizam como se os dominados tivessem feito do próprio conteúdo do mandado a máxima de suas ações (obediência). (WEBER, 1991, p. 190).

No caso da realidade brasileira, que doravante nos interessa de modo direto, é fundamental considerar que as relações patriarcais de gênero são indissociáveis das relações de classe e "raça"/etnia. Como está assertiva revela a partilha de uma tese, entendemos que categorias como patriarcado, racismo, sexualidade e classe existem de maneira dinâmica e em constante interação, de modo que "nenhuma categoria social existe em isolamento privilegiado; cada uma existe numa relação social com outras categorias, ainda que de modos desiguais e contraditórios" (MCCLINTOCK, 2010, p.

27).

Neste caminho, há incurso um processo de naturalização de tal domínio é intensificado a cada dia devido a este conservadorismo que assola o país definindo um conjunto de atitudes, comportamentos, percepções de mundo e normatização, cujo principal referencial é o fato da figura masculina se sobrepor, em diversos sentidos, ao feminino e sobre as demais minorias, como o público LGBTQI+.

Este pensamento conservador coloca a mulher em segundo plano, devido à dominação masculina se insere historicamente nos principais espaços de sociabilidade cotidianamente (Igreja, Família e Escola).

Há incurso um processo de naturalização de tal domínio é intensificado a cada dia devido a este conservadorismo que assola o país definindo um conjunto de atitudes, comportamentos, percepções de mundo e normatização, cujo principal referencial é o fato da figura masculina se sobrepor, em diversos sentidos, ao feminino.

Revista de Gênero, Sexualidade e Direito | e-ISSN: 2525-9849 | Encontro Virtual | v. 7 | n. 2 |

p. $62-76$ | Jul/Dez. 2021. 
Marafon e Castro e Souza (2018) fazem uma interligação entre o sistema neoliberal e o conservadorismo:

"Em vez de confrontar o sistema neoliberal quanto à produção de miséria que este confere à maior parte das populações e à preservação de riquezas para uma minoria, como fizeram os movimentos das chamadas primaveras árabes, os occupies estadunidenses e os "ocupas" brasileiros, os grupos conservadores se atêm a fabricar discursos e estratégias de poder que assegurem a conservação moralista de valores sociais que já foram dominantes para que não passem pela reterritorialização de forças que comprovem a cena pública. Além da postura ultraconservadora no terreno da moralidade privada, também se alinham a setores com posições ultraliberais na economia, que pregam um Estado mínimo no campo das políticas sociais na economia, diminuição dos investimentos públicos em políticas de redistribuição de renda e, paralelamente, são complacentes com o aumento de incentivos públicos às instituições privadas (e de cunho religioso) de saúde, educação, entre outras. São, ainda, favoráveis aos discursos do senso comum punitivista em voga nesses tempos sombrios, a ações penais mais rígidas, à promoção de práticas vingativas, à defesa das prisões moderrentas e até à pena de morte". (MARAFON; CASTRO E SOUZA, 2018, p. 77).

A sociedade contemporânea passou por inúmeras fases, onde há visões diferentes e opostas acerca da questão de gênero, entre as quais nos deparamos com a influência religiosa, econômica e política sobre a tais questões, definindo que a relação binária do gênero é heteronormativa, ao se posicionar na bipolaridade, entre homem e mulher.

\section{3- Os Estudos de gênero e as minorias sexuais e gênero}

Inicialmente, há uma dificuldade de conceituar gênero, em decorrência de sua multiplicidade elementos que o integram e a questão do binarismo; o processo da cultura patriarcal em sociedade; e, a heteronormatividade, segundo Butler (2017) e Bourdieu (2018).

Os elementos pontuais apresentados por Butler (2017), Bourdieu (2018) e, somados a estes, a leitura destes pesquisadores por Souza Jr (2018) e Sepuvelda e Sepulveda (2018) fazem concluir que os debates em relação à temática são de sua importância para a garantia dos direitos às minorias sexuais e de gênero.

Estas minorias sexuais e de gênero são conceituadas por Vecchiatti (2018) conceitua como: "As minorias sexuais são aquelas que são discriminadas social e/ou juridicamente em razão de sua orientação sexual ou de práticas sexuais dissonantes daquelas aceitas pelo moralismo majoritário,

Revista de Gênero, Sexualidade e Direito | e-ISSN: 2525-9849 | Encontro Virtual | v. 7 | n. 2 |

p. $62-76$ | Jul/Dez. 2021. 
desde que consensuais de equivalente capacidade civil). As tradicionais minorias sexuais, em termos identitários, são formadas por homossexuais (lésbicas e gays), bissexuais, pansexuais e assexuais. Heterossexuais configuram-se como maioria sexual.

As minorias de gênero são aquelas que são discriminadas social e/ou juridicamente em razão de sua identidade de gênero dissonante da cisgeneridade, ou em razão de hierarquias sociais que privilegiam um gênero em detrimento do(s) outro(s). Gênero se refere ao conjunto de características socialmente atribuídas e esperadas de uma pessoa em razão de seu genital, ao nascer. No binarismo de gênero culturalmente hegemônico, refere-se à dicotomia masculinidade/feminilidade. Então, a identidade de gênero se refere à autopercepção de uma pessoa enquanto pertence a um gênero. Transgênero é a pessoa que não se identifica com o gênero que lhe é atribuído ao nascer em razão de seu genital, nas culturas ocidentais). Cisgênera é a pessoa que se identifica com o gênero que lhe foi atribuído ao nascer (é a pessoa que não é trans para simplificar). Então as tradicionais minorias de gênero são as mulheres cisgênero e as pessoas transgênero - travestis, mulheres transexuais e homens trans. Cisgêneros configuram-se como a maioria de gênero". (VECCHIATTI, 2018, p. 452).

Em relação as minorias sexuais, concordamos com Maria Berenice Dias (DINIS, 2018), pois para ela a proteção prevista na lei em referência, deve ser estendida aos homens vítimas de violência doméstica, não importando, o sexo dos companheiros, já que as uniões homoafetivas constituem uma unidade doméstica, conforme decisão tanto do STF como do STJ.

Os estudos de gênero são observados durante a segunda e a terceira onda do feminismo; aquela foi marcada por Beauvoir (1980); e está por Angela Davis e Bell Hooks.

Os arranjos de gênero são formados através de uma relação binária onde é apresentado o "conceito patriarcal de gênero" (SAFFIOTI, 2004), sendo considerado como um eixo estruturante de relações simbólicas e materiais do normatizado como ser ou estar homem ou mulher, como mencionado por Henrietta L. Moore.

A masculinidade hegemônica penetra relações políticas e econômicas de uma maneira que assegura que a própria dominação é marcada por gênero. Grupos ou cabalas de homens heterossexuais - isto é, representados como heterossexuais - poderosos dominam tanto a condução dos estados modernos quanto as relações entre os estados, controlando assim os meios da força e da violência públicas. (...) É claro que essa forma hegemônica da masculinidade é acompanhada por uma forma hegemônica de racismo (MOORE, 2000, p. 33-34).

Este é marcado, como mencionado por Butler (2003), por um significado cultural e não apenas por um ato natural de caráter biológico, pois sempre será um fazer. Tal fato é reforçado por Foucault (1988) quando destaca o caráter normativo do sexo.

Para ele como para ela, o sexo é um "ideal regulatório" que não é parte de uma 'prática regulatória' que não funciona como norma, mas é parte de uma política reguladora que produz o que governa: o corpo (CAETANO, SILVA JUNIOR e 
GOULART, 2016, p. 129) e, o gênero "envolve a noção de que o poder é distribuído de maneira desigual entre os sexos, cabendo às mulheres uma posição subalterna na organização da vida social" (SORJ, 1992).

Estes estudos visam uma ruptura da relação binária de gênero, apoiandose na desconstrução da identidade de gênero com a finalidade de preservar a performance de gênero, problematizando, assim, as diferenças biológicas atribuídas à natureza dos sexos, a demanda e a autonomia das mulheres.

Por exemplo, uma mulher lésbica masculinizada branca pode ser mais aceite que uma lésbica não masculinizada negra e pobre (SILVA, 2015, p. 5). Esta identidade "é um significado - cultural e socialmente atribuído" (SILVA, 2014, p. 89) ao sujeito em sociedade.

O gênero é em simultâneo, a identidade sexual assinalada pela sociedade (o masculino e o feminismo) e o que o sujeito vai escolher em sua orientação sexual, ou seja, "é uma interpretação política e cultural do corpo, não existindo, por conseguinte, a distinção sexo/gênero em linhas convencionais; o gênero é embutido no sexo, e o sexo mostra ter sido gênero desde o início", segundo Butler (2017, p. 197) em um determinado corpo.

Este corpo é controlado pelo sexo produzindo as bases, os limites e as diferenças em que atua, este é um "ideal regulatório", conforme alude Foucault (1998), que não só funciona como norma, mas é parte de uma prática reguladora que produz o que governa, ou seja, como mencionado por Goellner (2017),

"Falar de corpo é falar, também de nossa identidade dada a centralidade que este adquiriu na cultura contemporânea cujos desdobramentos podem ser observados, por exemplo, no crescente mercado de produtos e serviços relacionados ao corpo, a sua construção, aos seus cuidados, a sua libertação e, também, ao seu controle". (GOELLNER, 2017, p. 31),

Ao longo da história e nas mais diferentes culturas, o corpo foi construído e pensado tomando, assim, vários formatos e definindo identidades e ao mesmo modificando-as. Assim, o corpo imprime a marca da vida social e deve ser educado para produzir e reproduzir um determinado padrão normativo vigente de uma matriz heterossexual, a qual determina os padrões e as pautas que geram transgressões.

Para Drumont (1980):

"[...] em termos de colocação adotada, o machismo é definido como um sistema de representações simbólicas, que mistifica as relações de exploração, de dominação, de sujeição entre o homem e a mulher, reduzindo-os os sexos hierarquizados, divididos em polo dominante e polo dominado que se confirmam mutuamente numa situação de objetos". (DRUMONT, 1980, p. 81).

É uma referência a ele que se fazem não apenas aos corpos que se conformam às regras de gênero e sexuais, mas também aos corpos que as subvertem (LOURO, 2016, p. 17) que serão alvo de constante escrutínio e sofrerão as sanções sociais inerentes.

Há denúncias de discursos de ódio em face dessas pessoas que produzem narrativas sobre a tais questões e casos relacionados à não realização de atividades que representam tal questão, em consequência deste fato, as conquistas sociais e políticas dos movimentos que buscam uma política de reconhecimento das diferenças começam a serem dilapidadas, 
voltando à estaca zero, devido ao não reconhecimento do diferente e de suas marcas de diferenças.

\section{4- A ideologia de gênero, o machismo e a sociedade atual}

A questão de gênero, na presente sociedade conservadora e tradicional, é considerada como uma construção falsa, que nega a verdade da diferença sexual e, ao criticam, tal momento, produzindo uma confusão sobre os termos ligados ao gênero e ao mesmo tempo identificando um dado inexistente, a chamada "Ideologia de Gênero, ou melhor dizendo, a Ideologia da Ausência de Sexo, é uma crença segundo a qual os dois sexos - masculino e feminino - são considerados construções culturais e sociais [...]" (SOFOS, 2017).

Nota-se a evolução de um ativismo religioso reacionário que busca mobilizar seus adeptos sobre o conceito "ideologia de gênero", em que são impostos valores morais e doutrinas cristãs que não comungam com a família contemporânea e com ações pedagógicas que promovam os direitos sexuais, a igualdade sexual e de gênero e o reconhecimento da diferença/diversidade sexual e de gênero, como mencionado por

António Guterres, secretário-geral das Nações Unidas, em mensagem pela passagem do Dia Internacional das Mulheres, em 08 de março de 2018,

As desigualdades históricas e estruturais que deram origem à opressão e à discriminação estão aparecendo como nunca. Da América Latina à Ásia, através da Europa, nas redes sociais, conjuntos de filmes, fábricas e ruas, as mulheres pedem uma mudança duradoura e que não sejam toleradas agressões sexuais, assédio nem tipo de discriminação. Alcançar a igualdade de gênero e empoderar mulheres e meninas são tarefas pendentes do nosso tempo e constituem o maior desafio em termos de direitos humanos no mundo.

Este combate tem se mostrado importante dentro do discurso neoconservador, na medida em que promove a eliminação de temas progressistas em nome da família tradicional, fragiliza demandas sociais problemáticas ao produzir uma incerteza quanto ao tipo e características das mudanças propostas, e intensifica as que estão articuladas com o mercado econômico.

De forma geral, Junqueira (2018) analisa os documentos vaticanais e episcopais e salienta que produziram vários subnomes para a "ideologia de gênero" e que, hoje, são acompanhados pela bancada religiosa do Congresso Nacional.

Em 1998, o Papa João Paulo II estava preocupado com a questão sobre a influência do conceito de gênero sobre a "família tradicional", a "verdadeira feminilidade" ou a "verdadeira masculinidade" por isso, divulgou a encíclica (carta apostólica) intitulada "Sobre a dignidade e a vocação da mulher" (Mulieris dignitatem), onde lembrava a todos o papel da mulher para a maternidade e que suas funções eram diversas aos homens.

Nesta mesma linha, e com maior critica a teoria de gênero, em 2012, o Papa Bento XVI, proferiu seu discurso de Natal, assim se posicionando, 
"De acordo com esta filosofia, o sexo já não é considerado um elemento dado pela Natureza e que o ser humano deve aceitar e estabelecer um sentido pessoal para a sua vida. Em vez disso, o sexo é considerado pela Ideologia de Género como um papel social escolhido pelo indivíduo, enquanto no passado, o sexo era escolhido para nós pela sociedade. A profunda falsidade desta teoria e a tentativa de uma revolução antropológica que ela contém, são óbvias".

Peeters (2013) teórica da “ideologia de gênero", assim se posiciona:

"A análise mostrará que, em nome de uma interpretação cidadã e secular da igualdade, unicamente entendida como poder e direitos, o processo revolucionário de gênero mina cultural, política e legalmente a identidade constitutiva do homem e da mulher como pessoas: suas identidades como cônjuges, suas maravilhosas complementaridade e unidade no amor, sua vocação e papel educativo específicos, a masculinidade e a feminilidade, o casamento e a família, a estrutura antropológica de qualquer ser humano, construída sobre um amor dado, recebido e compartilhado". [trad. livre]. (PEETERS, 2013, p.9)

O Conselho Pontifício para a Família, sob a presidência do cardeal Alfonso López Trujillo, que é um opositor à Teologia da Libertação, contrário ao uso de preservativos, ao casamento homossexual etc, publica um extenso dicionário enciclopédico sobre a temática, em 2003, intitulado Lexicon: termos ambíguos e discutidos sobre a família, vida e questões éticas (PONTIFICIO Conselho para a Família, 2006).

Junqueira (2018) assim se posiciona sobre ele: “[..] em relação à educação sexual, opta pela atenção à família e define os limites desta educação no âmbito escolar, além de se

opor ao feminismo, onde define que sexo e sexualidade são elementos pertencentes à ordem transcendente, pré-social, natural e imutável". (GARBAGNOLI, 2014apud JUNQUEIRA, 2018)

Em 31 de maio de 2004, o Papa João Paulo II se pronunciou sobre a questão em "Carta aos bispos", na qual se manifestou contra o discurso feminista, reiterando que a maternidade era um elemento-chave da identidade feminina.

Outro registro importante para a temática é a publicação, em 2010, da obra intitulada La ideologia de género o el género como herramienta de poder ${ }^{3}$, por Jorge Scala, que é tida como referência por parte das autoridades católicas brasileiras para esta temática, além do I Congresso Internacional de Ideologia de Gênero com base no pensamento católico tradicionalista, ocorrido em fevereiro de 2011, na Universidade de Navarra.

\footnotetext{
${ }^{3}$ A ideologia de gênero ou gênero como ferramenta de poder [tradução livre]
} 
O papa Bento XVI ${ }^{4}$, em 21 de dezembro de 2012, ao proferir seu discurso conclamando o Natal, foi enfático ao salientar que a Igreja deveria se manifestar ublicamente sobre a proibição da difusão do conceito de "gender", já que seus debates poderiam desintegrar o ser humano.

As pessoas [que promovem a Ideologia de Género] denegam a questão de gênero por entender que a identidade corporal é a que serve como um elemento definidor do ser humano. Elas negam a sua natureza e decidem que não é algo que lhes foi previamente dado, mas antes que seja algo que elas próprias podem construir.

Por meio deste discurso, a Igreja se posicionou sobre a temática e, por conseguinte, autorizou a difusão de seu posicionamento por intermédio dos meios de comunicação, originando, assim, um movimento antigênero dentro dos países em que a Igreja Católica se faz presente.

Rafael Solano (2016) enumera três consequências em relação à "ideologia de gênero, na atualidade, quais sejam: negação da família; fortalecimento do relativismo; e eliminação da pessoa (SOLANO, 2016, p. 33/38).

O ano de 2013 foi marcado pela mobilização contra a "ideologia de gênero", oriunda tanto da Igreja Católica como da direita, em diversas cidades francesas, que coloriram as ruas com cores rosa e azul de suas bandeiras. Marguerite Peeters (2013), teórica da "ideologia de gênero", assim se posiciona:

A análise mostrará que, em nome de uma interpretação cidadã e secular da igualdade, unicamente entendida em termos de poder e direitos, o processo revolucionário de gênero mina cultural, política e legalmente a identidade constitutiva do homem e da mulher como pessoas: suas identidades como cônjuges, suas maravilhosas complementaridade e unidade no amor, sua vocação e papel educativo específicos, a masculinidade e a feminilidade, o casamento e a família, a estrutura antropológica de qualquer ser humano, construída sobre um amor dado, recebido e compartilhado (PEETERS, 2013, p. 9) [trad. livre].

O ano de 2013 foi marcado pela mobilização contra a "ideologia de gênero", oriunda tanto da Igreja Católica como da direita, em diversas cidades francesas, que coloriram as ruas com cores rosa e azul de suas bandeiras. Em 2016, foi proposto novo ataque ao gênero, como ideologia "diabólica e marxista", que impactou, negativamente, o acordo pela Paz na Colômbia, como mencionado por Marco Aurélio Maximo Prado e Sonia Correa (2018).

E, por fim, a ida ao segundo turno das eleições presidenciais, na França, de um candidato de extrema direita, a chegada ao poder na Colômbia de um conservador, que fez o Congresso adiar a aprovação do regulamento da Justiça Especial para a Paz (JEP), e o discurso de Jair Bolsonaro, em 2019, destinado ao Congresso Nacional, como um de seus objetivos, que será o combate à "ideologia e gênero".

\section{5- Conclusão}

\footnotetext{
${ }^{4}$ Papa Bento XVI da Igreja Católica, nascido Joseph AloisiusRatzinger, Seu papado iniciou-se em 19.04 .2005 e terminou com sua renúncia em 28 de fevereiro (https://w2.vatican.va/content/benedictxvi/pt.html, acesso em 19 de ago de 2019).
}

Revista de Gênero, Sexualidade e Direito | e-ISSN: 2525-9849 | Encontro Virtual | v. 7 | n. 2 | 
A defesa da interpretação literal do texto bíblico de cristãos, católicos ou evangélicos fazem se posicionarem contra de qualquer aspecto do evolucionismo científico em defesa do criacionismo bíblico, sendo a intolerância com a cultura e crença alheias, a pouca abertura ao diálogo e a interdição em grupo suas principais características visam privilegiar a cultura patriarcal, o machismo e a heteronormatividade.

A influência deste "pensamento fundamentalista e (neo)conservador" é, na verdade, o conjunto de teorias que versam sobre a questão da "ideologia de gênero, conceito criado pela Igreja Católica e aceito pelas Igrejas Pentecostais no Brasil, como forma de respeito à família tradicional que não permite que o debate de questões ligadas ao gênero e a diversidade sexual.

Os sujeitos dissidentes e divergentes da relação de gênero, ou seja, as minorias sexuais e de gênero, se expressam através de seus corpos ao apresentarem suas diferenças e marcações de fronteiras que necessitam que seus locais de fala seus preservados.

$\mathrm{O}$ respeito a estes diferentes e a suas diferenças são proposituras importantes que visam garantir a dignidade humana dos divergentes ou dissidentes da questão do gênero.

Estas identidades múltiplas são dotadas de características que marcam diferentes situações e posições sociais, as quais podem indicar preconceito e discriminação em relação a determinadas pessoas ou suas performances em sociedade, como por exemplo, a mulher poderá ser lésbica, negra/branca, idosa/jovem ou pobre/rica.

Ao se pensar nestas performances identitárias nos deparamos com sujeitos que vivem e se apresentam de determinada forma socialmente, entretanto, devido à complexidade da vida, há necessidade que estes assumam diferentes identidades, as quais são criadas por marcadores de diferenciação, onde podemos incluir a: etnia, raça, gênero e sexualidade, entre outros fatores.

A identidade sexual é aquela que identifica a atração da pessoa por outra; já, a identidade de gênero é como a pessoa se identifica em sociedade, podendo ser cis ou trans.

Por outro lado, ao identificarmos uma pessoa como heterossexual, homossexual ou bissexual estaremos diante do conceito de orientação sexual, pois este observa como cada pessoa age, pensa sobre si mesma e em relação a sua sexualidade e por quem ela é atraída.

Entre o gênero e a sexualidade há diferenças, onde o primeiro é um conjunto de representações sociais, históricas e culturais, assim, não sendo determinados por estruturas biológicas e, por isso, não revelam a sexualidade do sujeito; e, a segunda, embora tenha fundamento num corpo biológico, dever ser observada como uma construção social.

Como forma de enfrentamento destes fatos, há necessidade de debatermos em Congressos, Seminários e através de nosso engajamento na luta pela busca do reconhecimento das pessoas divergente de gênero, seu local de fala que visa o fortalecimento de políticas identitárias capazes de garantir à dignidade e o respeito às diferenças.

\section{Referências Bibliográficas}

AKOTIRENE, Carla. Interseccionalidade. São Paulo: Sueli Carneiro: Pólen, 2019.

BAUMAN, Z. Identidade. Entrevista a Benedetto Vecchi. Rio de Janeiro. Jorge Zahar. 2005 . 
BIANCHI, Alvaro. Neoconservadorismo, neoliberalismo e neofundamentalismo. IN:

$\begin{array}{llllll}\text { Revista } & \text { Cult, } & 13 & \text { de }\end{array}$

https://revistacult.uol.com.br/home/neoconservadorismo-neoliberalismo-

eneofundamentalismo, acessado em 10 ago de 2019.

BRITZMAN, D. Curiosidade, sexualidade e currículo. In: LOURO, G. (org). O corpo educado: pedagogias da sexualidade. Belo Horizonte: Autêntica, 2001, p. 83-112.

O que é esta coisa chamada amor. Educação e Realidade. Porto

Alegre, v. 21, n. I, p. 71-96, jan/jun, 1996.

BOURDIEU, Pierre. A dominação masculina; trad. Maria Helena Kühner. $6^{\mathrm{a}}$ ed. Rio de Janeiro: BestBolso, 2018.

BONAZZI, T. Conservadorismo. In: BOBBIO, N.; MATTEUCCI, N.; PASQUINO, G. (Orgs.). Dicionário de política Brasília: Editora da UnB; São Paulo: Imprensa Oficial , 2000. v. 1. p. $242-246$

BUTLER, Judith, Problemas de Gênero - feminismo e subversão da identidade. Rio de Janeiro: Editora Civilização Brasileira, 2003

CARNEIRO, Sueli. Racismo, sexismo e desigualdade no Brasil. São Paulo: Selo Negro, 2010.

COSTA, Fabiano da Silva. Lima Barreto: o Brasil sob a ótica do Dr. Bogóloff.

Dissertação (mestrado). Orientador: Nelson Luís Ramos. Universidade Estadual Paulista

"Júlio de Mesquita Filho", Instituto de Biociências, Letras e Ciências Exatas. São José do Rio Preto, 2015

DRUMONT, Mary Pimentel. Elementos para uma análise do machismo. São Paulo:

Perspectivas, 3, 1980, p. 81-85. (disponível em:

http://seer.fclar.unesp.br/perspectivas/article/viewFile/ 1696/1377).

FOUCAULT, Michel. Em defesa da sociedade: curso no College de France

(19751976). São Paulo: Martins Fontes, 1999.

GIDDENS, Anthony; PIERSON, Christopher. Conversas com Anthony Giddens. Rio de Janeiro: FGV, 2000. LÉVY, Pierre. As tecnologias da inteligência.

GOELLNER, Silvana Vilodre. A produção cultural do corpo. IN: LOURO, Guacira Lopes Louro; FELIPE, Jane; GOELLNER, Silvana Vilodre Goellner (orgs). Corpo, gênero e sexualidade: um debate contemporâneo na educação. 9a ed. Petrópolis, RJ: Vozes, 2013.

HALL, Stuart. Pensando a diáspora: reflexões sobre a terra no exterior. In: Da diáspora Identidades e mediações culturais. Belo Horizonte, Editora UFMG/UNESCO, 2003.

Quem precisa de identidade? In: SILVA, Tomaz Tadeu da (org.). Identidade e diferença: a perspectiva dos Estudos Culturais. $15^{\mathrm{a}}$ ed. Petrópolis, RJ. Vozes, 2014, pp. 7-72.

HEILBORN, Maria Luiza. Dois é par - gênero e identidade sexual em contexto igualitário. Rio de Janeiro: Garamond, 2004.

MARAFON, Giovanna e ROSA, Marina Castro. Como o discurso "ideologia de gênero" ameaça o caráter democrático e plural da escola? IN: FRIGOTTO, Gaudêncio; QUEIROZ, Felipe; PENNA, Fernando (org). Educação Democrática: antídoto ao Escola Sem Partido. Rio de Janeiro: UERJ, LPP, 2018, p. 75 a 88.

Revista de Gênero, Sexualidade e Direito | e-ISSN: 2525-9849 | Encontro Virtual | v. 7 | n. 2 |

p. 62 - 76 | Jul/Dez. 2021. 
MISKOLCI, R. Um corpo estranho na sala de aula In: ABRAMOWICZ, Anete e KOLONTAI, Alexandra. A nova mulher e a moral sexual. 2. ed. São Paulo: Expressão Popular, 2011.

LOURO, Guaraci Lopes. O Corpo educado: Pedagogias da sexualidade. $4^{\mathrm{a}}$ ed. Belo Horizonte: Autêntica, 2019.

OLIVEIRA, Rosane Cristina; LIMA, Jacqueline de Cássia Pinheiro; GOMES, Raphael

Fernandes. Machismo e discurso de ódio nas redes sociais. Revista Feminismos: vol,

6, $\quad \mathrm{n}^{\mathrm{o}} \quad$ 1, jan-abr, 2018. Disponível:

https://periodicos.ufba.br/index.php/feminismos/article/view/30363. Acesso em 05 de ago de 2021.

RIBEIRO, Djamila. Lugar de fala. São Paulo: Sueli Carneiro; Pólen, 2019.

RIOS, Roger Raupp. Direito da antidiscriminação: discriminação direta, indireta e ações afirmativas. Porto Alegre: Livraria do Advogado, 2008.

do Advogado, 2001.

A Homossexualidade no direito. 1ed. Porto Alegre: Editora Livraria

SALIM, Sara. Judith Butler e a Teoria Queer; trad e notas Guacira Lopes Louro. Belo Horizonte: Autêntica Editora, 2017.

SARLET, Ingo Wolfgang. Dignidade da pessoa humana e direitos fundamentais na

Constituição Federal de 1988.7 ed. Porto Alegre: Livraria do Advogado, 2009.

SILVA, Ariana Kelly Leandra Silva da. Diversidade sexual e de gênero: a construção do sujeito social. Rev. NUFEN vol.5 no.1 São Paulo, 2013 Disponível em http://pepsic.bvsalud.org/scielo.php?script=sci_arttext\&pid=S217525912013000100003

Acesso em 10 de julho de 2018.

SEPULVEDA, Denize e SEPULVEDA, José Antonio. Conservadorismo, gêneros e sexualidades: temáticas que se entrelaçam nas pesquisas do GESDI e do GEPCEB. In:

AMARO, Ivan e SEPULVEDA, Denize (org.). Gêneros, sexualidades e educação na ordem do dia. Curitiba: CRV, 2018, p. 45 a 66.

SILVA, Cristiane Gonçalves da. Semana 3 - orientação sexual, identidades sexuais e

identidade de gênero.

http://www.comfor.unifesp.br/wpcontent/docs/COMFOR/biblioteca virtual/GDE/mod 3/Semana3_Mod3_GDE.pdfm.

Acesso em 10 de ago de 2021.

SILVA, Ivanderson Pereira da Silva. Em busca de significados para a expressão

“ideologia de gênero". In: Educ. Rev. . vol.34. Belo Horizonte, 2018, Epub Dec 13, 2018. http://dx.doi.org/10.1590/0102-4698190810. Acesso em 10 de ago de 2021.

SILVA, Tomaz Tadeu da Silva. A produção social da identidade e da diferença In:

SILVA, Tomaz Tadeu da (org.) Stuart Hall, Kathryn Woodward. Identidade e diferença: a perspectiva dos Estudos Culturais. SILVA. 15 a ed. Petrópolis, RJ. Vozes, 2014. SOUZA Jr. Paulo Roberto de. A construção de uma política identitária voltada ao negro e sua marcação de diferença como forma de eliminar desigualdades raciais. Revista Movimentos Sociais e Conflitos: $\quad v$. 4, n. 2 (2018). Disponível: https://www.indexlaw.org/index.php/revistamovimentosociais/article/view/4832.

Acesso em 10 ago 2021.

A questão de gênero, sexualidade e orientação sexual na atual base nacional comum curricular (BNCC) e o movimento LGBTTQIS.

Revista de Gênero, Sexualidade e Direito | e-ISSN: 2525-9849 | Encontro Virtual | v. 7 | n. 2 |

p. $62-76$ | Jul/Dez. 2021. 
Revista de Gênero, Sexualidade e Direito. Revista de Gênero, Sexualidade e Direito: v. 4, n. 2 (2018). Disponível: https://indexlaw.org/index.php/revistagsd/article/view/3924. Acesso em 10 ago 2021.

VECCHIATTI, Paulo Roberto Iotti. Mobilização judicial pelos direitos da diversidade sexual e de gênero no Brasil. In: História do Movimento LGBT no Brasil. James N.

Green. Renan Quinalha. Marcio Caetano. Marisda Fernandes (orgs.). São Paulo: Alameda, 2018, pp. 449-470.

WALBY, Silvia. From private to public patriarchy. In: WALBY, Silvia. Theorizing patriarchy. Oxford: Basil Blackwell, 1990. p. 173-202.

WEBER, Max. Sociologia da dominação. In: WEBER, Max. Economia e sociedade. Brasília: UnB, 1991. p. 187-223.

WOODWARD, Kathryn. Identidade e diferença: uma introdução teórica e conceitual. In: SILVA, Tomaz Tadeu da (org.). Identidade e diferença: a perspectiva dos estudos culturais. 15. Ed. Petrópolis: Vozes, 2014, pp. 103-133. 